Editorial

\title{
Inclusive Technologies and Learning: Research, Practice and Policy
}

\author{
Don Passey
}

Department of Educational Research, Lancaster University, Lancaster, LA1 4YD, UK; E-Mail: d.passey@lancaster.ac.uk

Submitted: 21 December 2015 | Published: 28 December 2015

Keywords

digital technologies; disability; education; learning; social inclusion

\section{Issue}

This editorial is part of the special issue "Inclusive Technologies and Learning", edited by Don Passey (Department of Educational Research, Lancaster University, UK).

(C) 2015 by the author; licensee Cogitatio (Lisbon, Portugal). This article is licensed under a Creative Commons Attribution 4.0 International License (CC BY).

\section{Background and Focus of this Special Issue}

This special issue focuses on an important contemporary concern-inclusive technologies and learning. Since the 1960s there has been a continued development and diversification of digital technologies used across societal sectors (Bijker, Hughes, Pinch, \& Douglas, 2012), enabling applications not solely within business and commerce, but significantly within educational and social settings (such as those discussed by The Metiri Group, 2006, for example), supporting communication and learning (for example, shown by Richardson, 2012), providing opportunities to widen and deepen reach and interactions (as indicated, for example, by Kim, Hagashi, Carillo, Gonzales, Makany, Lee, \& Gàrate, 2011). It can be argued that such developments have created many divisions and challenges too (Resta, \& Laferrière, 2008); individuals as well as nations may not have the same access or facilities as others (ITU, 2015); and issues such as exploitation and exclusion are regularly highlighted (Dutta, Geiger, \& Lanvin, 2015). This special issue is concerned with inclusive technologies and learning, related to social inclusion. Key questions considered in the papers selected for this special issue include:

- For learning, training or employment, do digital technologies enable social inclusion within educational or training settings (helping to address the range of problems identified in the extensive study of Vaughn, Wexler, Beaver, Perron, Roberts, \& Fu, 2011, for example)?
- Are digital technologies being developed to enhance learning and social inclusion (such as the way the development of virtual worlds is described by Doyle, 2010, for example)?

- How are online learning and social networking practices influencing social inclusion in learning (engaging in practices and realising outcomes in the forms detailed in Coomey, \& Stephenson, 2001, for example)?

- Do digital technologies benefit certain groups to greater extents, or specifically, in terms of learning related to social inclusion (in situations such as those discussed by Campigotto, McEwen, \& Epp, 2013, for example)?

- Do digital technologies support learning and social inclusion across all ages, in terms of intergenerational learning, and independent of cultures (through processes such as those described by Palaigeorgiou, Triantafyllakos, \& Tsinakos, 2011, for example)?

In this special issue, six papers are presented, each providing a different perspective, but all focusing on inclusive technologies and learning. Whilst all six papers offer different views, there is, however, a common message that emerges from across these six papers; that is-there is a vital need for research in the field of inclusive technologies and learning to continue to explore ways that allow individuals who have disabilities or communication needs to collaborate and be involved in research activities if we are to effectively 
identify outcomes that can be applied purposefully through policy and practice.

\section{Research, Practice and Policy Perspectives}

In essence, these six papers offer perspectives that throw light on the research, policy and practice arena. In the field of inclusive technologies and learning, the three elements of research, policy and practice are seen and recognised as being necessarily closely connected and affected:

- Research in this field can (and it is argued, should) draw out findings that have implications for policy and for practice.

- Policy should take research and practice into account if it is to afford voice to those with disabilities or communication needs that are a part of an inclusive community or population.

- Practice should not only be aware of policy and research in this field, but should review regularly what effects this awareness is having on activity and on outcomes in terms of learning.

Although these six papers have clear and important messages and implications for policy, it is interesting that few policy makers have been involved directly in that research. The research that is reported has focused mainly on gathering evidence from learners and from teachers. But the three audiences of researchers, policy personnel and practitioners are all important in the context of these papers. A way of considering this is to think of the actors being influenced by an audience 'slice' (shown in Figure 1).

Thinking about this form of relationship through each of the papers, important emerging points from each of them arise.

\section{An Overview of Each Paper with Key Emerging Points}

McDowell (2015) offers a qualitative case study of an undergraduate university cohort, exploring the ways that online learning can support individuals on the autistic spectrum in engagement with group work. This case study investigates practices that teachers provide, where the teacher is also the researcher. However, the focus is clearly on the learners, undergraduates in a university course. The paper raises questions-how can group work be effectively managed to include learners on the autistic spectrum, and what are the implications for practice and policy? The paper argues from a practice viewpoint that there is a need to strongly consider these questions. What will happen beyond the course and the university context is certainly not clear, and how the involvement that has been achieved can be supported in the long term for these learners is not within the gift of those undertaking the study or even within the institution of the learners. This paper shows that while practice clearly needs to consider how to support collaborative and group work when cohorts include individuals on the autistic spectrum, policy at a local and wider level importantly needs at the same time to recognise the importance for individuals on the autistic spectrum to be able to work in groups. Taking this practice forward may well, therefore, be a concern not just at a local university level, but at national and international policy focus levels too. In terms of Figure 1 , the study directly involves the research and practice slices, but has vitally important messages and implications for the policy slice.

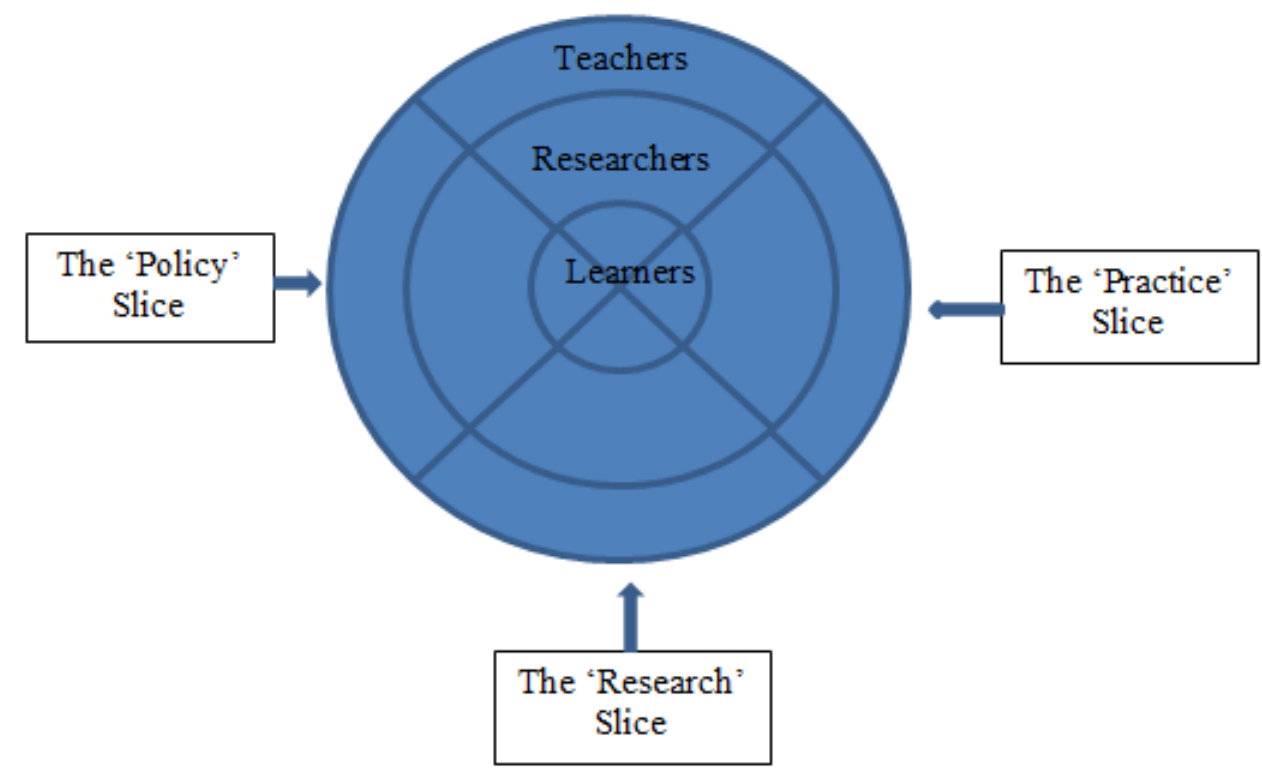

Figure 1. A relationship of actors and audience. 
Davidson (2015) provides a contrasting study, a collaborative action research study, which looks at how adult learners living with an intellectual disability can be involved in producing videos that tell their story and gives others access to their achievements and successes. The study focuses on the learners, adult learners, but also investigates how they are supported by and interact with 'counsellors' and other adults in the community. Whilst the study focuses on how to involve these learners in video production, rather than them being involved in simply receiving information or ideas through video channels, the questions of who can lead this for individuals beyond the study, and who can take this practice forward, are important if the successes of this work are to be seen more widely. The paper raises questions of how individuals with intellectual disabilities can be effectively involved in producing rather than receiving through video, and how this will be done in other contexts by others in the future. The author provides an effective model that is linked to a supportive context, but how this can and will be replicated is a question that goes beyond the study itself. From a policy perspective, there is clearly a need for policy makers to be aware of the fact that involving those with intellectual disabilities in producing rather than receiving through video is an important practice to develop and support. Taking this practice forward, local, national and international support structure policy focus groups can all play a part. Again, in terms of Figure 1, the study involves the research and practice slices, but has vitally important messages and implications for the policy slice.

Hayhoe, Roger, Eldritch-Böersen and Kelland (2015) provide us with evidence from a case study, undertaken in a university undergraduate context, concerned with developing what they term inclusive technical capital' to counter effects of changes in policy for supporting university-level students with disabilities. The study focuses on the learners, but the role of the researchers is clearly important in creating potentially positive alternative activities for the learners to gain basic study skills. While teachers are less directly highlighted in this study, it clearly raises questions of how mobile technologies and drop-in sessions can effectively support students with disabilities in enhancing their basic study skills in universities when allowances are being changed. In this context, finding out that mobile technology-based activities and uses of virtual learning environments (VLEs) appear to be favoured by learners, clearly has implication for policy and practice. The authors indicate the importance of mobile technologies and VLEs in this situation, but how these technologies can most effectively be used in practice, and who will model this practice, are also questions for policy. Outcomes of the study imply that there is a need to consider appropriate and relevant policy at individual, institutional and national levels to recognise ways to effectively support students with disabilities, with practice seeking to introduce ways that are effective for students with disabilities. Taking this practice forward, local university policy focus will clearly be an important next step. In terms of Figure 1, the study informs us through the research and practice slices, with clear messages and implications for the policy slice.

Hardman (2015) reports a study using an action research approach, involving mixed method data gathering, exploring how teachers supporting special education can be prepared and updated in their practices through community building using Web 2.0. This study focuses on teachers and their practices, specifically on teacher trainees and teachers in the compulsory school sector. However, the researcher has a clear role too, in providing facilities and support for the building of a community. With low levels of contribution by the teachers following their graduations, the study raises the questions of whether communities of practice work in supporting ongoing practice in all cases through their involvement as observers, whether there are specific difficulties for teachers working with special education in contributing in these ways, and what limits that use. While it is clear that there is a need for these teachers to be using technologies in order to be as aware as possible of how to support children with special needs with technologies, and for them to keep abreast of new developments, how this should be done is not clear from the study outcomes. It is refreshing, however, to see an example of activities that do not work in an entirety. For practitioners, this leaves the question open of how to set up such a network to support this necessary community, and for policy personnel, questions of how the need for those supporting special education to share understandings, experiences and practices through their careers can be addressed. Taking practice forward, there are clear implications for local teacher training, as well as for regional and national policy focus in this respect. In terms of Figure 1, the study informs us of outcomes through the research and practice slices, but leaves important questions and implications for the policy slice.

Parsons (2015) offers a policy review and analysis, looking in depth at the ways that digital technologies might positively affect informed consent practices with children and young people in social research. The author focuses on the learners in this paper, across the age range, highlighting how technologies can now afford positive ways to bring forward and highlight learner voice more effectively, as well as to ensure informed consent is more ethically focused. While teachers are not the main focus of this paper, there are clearly implications for teachers in how they respond to and handle these new opportunities. The paper raises questions about whether our current ethical processes are always ethical (or whether they sometimes might be considered unethical), and whether they do 
really achieve the purpose they are set out to do. Considering the legal element in these practices leads to questions as to whether ethics are now more focused on legal concerns than ethical concerns, how the two relate, and whether the 'old practice' of 'signing on the dotted line' has become a practice that ethics adopts without sufficient critical question. For practice, there is a clear need for teachers to consider how informed consent can be structured to ensure children and young people (including those with disabilities and communication needs) have a significant voice in social research, while for policy, reviewing the practice of informed consent to ensure children and young people have a significant voice in social research is a clearly vital need. Taking this practice forward, there are certainly implications for groups considering this issue at national and international levels as well as at local and agency policy focus levels. This paper again, in terms of Figure 1, informs us through the research and practice slices, but has vitally important messages and implications for the policy slice.

Burgstahler (2015) provides a review of practice and research concerned with the progress of developments that support engagement and access through online learning practices for university students with disabilities (particularly in terms of visual, auditory and motor disabilities). In this paper, the experience of the researcher, and the experiences of teachers in universities, are brought forward and examined in terms of the recent development of effective practice within an overall policy concern-for making online learning practices accessible for those with disabilities. The paper raises questions of what has been achieved in terms of supporting students with disabilities to engage with and use online environments over the past years, and what has failed. Overall, the author paints a fairly disappointing picture of university practices not moving towards wide-scale concern and implementation. If outcomes at this time are not as positive and wide-spread as had been hoped for, it is possible that moving forward might require new technological approaches to these issues, as well as considering further ways to influence practice and policy more widely. For policy, it is important that the current state of play is recognised, while for practice, it is important for teachers and those managing courses to identify what needs to be done, now and in the future. Taking this practice forward is likely to require a focus not just from the local university, but also at national policy focus levels, including discussions with technology providers and innovators. In terms of Figure 1, the review informs us through the research and practice slices, but again has important messages and implications for the policy slice (including particularly innovative technology policy).

Overall, the six papers in this special issue highlight the ways that researchers in this field have been actively engaged in supporting and drawing out findings from learners and teachers that have relevance not just for the practice and research slices, but also for the policy slice (illustrated in Figure 2).

These papers highlight our need for practice and policy to have appropriate and regular concern for inclusive technologies and learning, to accommodate and consider:

- In adult learning settings, how video production might support collaborative work and engagement for individuals with intellectual disabilities.

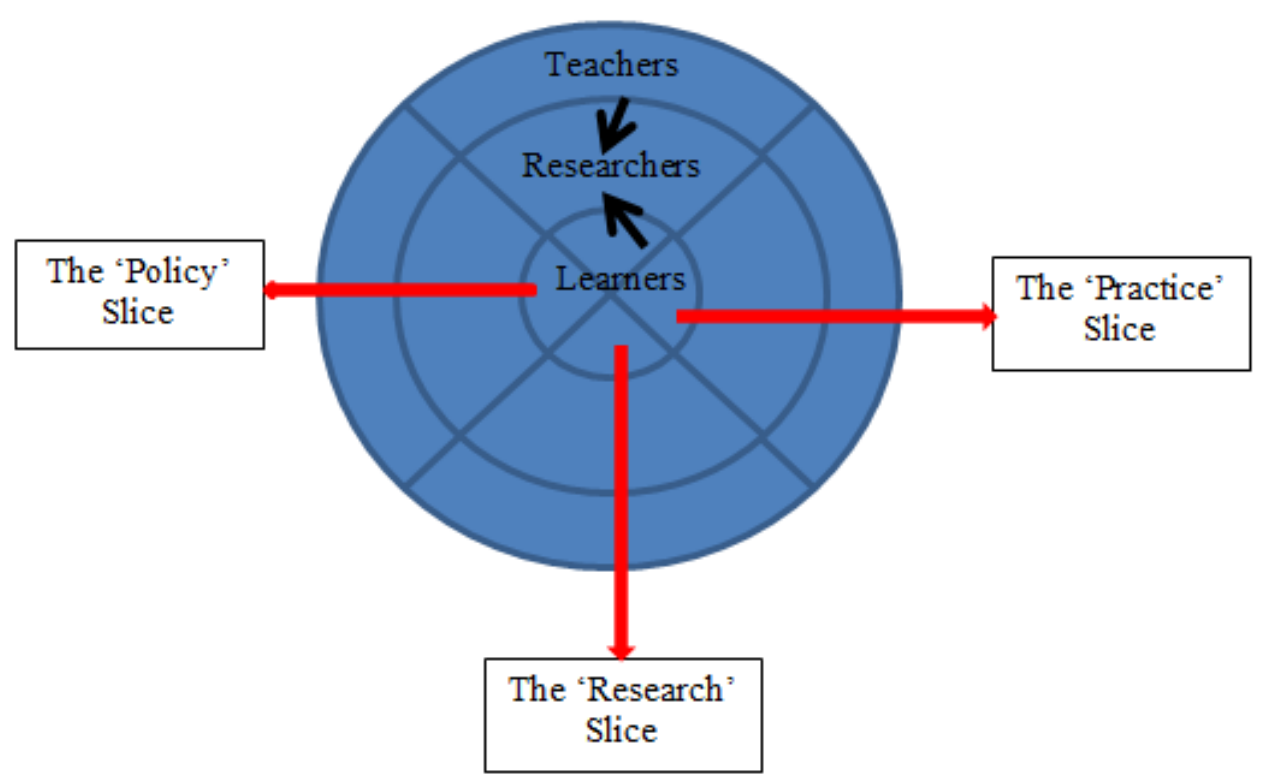

Figure 2. The approach taken by the researchers in this special issue. 
- In universities and institutions of higher education, how online environments might support group work for individuals on the autistic spectrum, how mobile technologies and VLEs might support 'inclusive technical capital' approaches for individuals with disabilities, and how regular review of the provision of online learning practices (including innovative technology review) is required to ensure access for individuals with visual, auditory or motor disabilities.

- In compulsory school settings, how ongoing support for teachers of special education might be appropriately provided, and how technologies both challenge and can support ethical consent practices more effectively to enable learner voices for individuals, including those with disabilities and communication needs, to be heard.

\section{Adding to Our Depth and Breadth of Knowledge}

From a review of literature focusing on inclusive technology enhanced learning, I identified recently a list of major gaps in our research knowledge and understanding (Passey, 2013). The review suggested the need for us to 'understand more about certain groups of learners, as well as about certain ranges of educational digital technologies and their applications in the field of practice' (pp. 208-209). The list of gaps identified, included our need to have more evidence about:

- 'Impacts of different categories of digital technologies on long-term memorisation and the development of social and societal aspects of learning.'

- 'Uses, outcomes and impacts of project and afterschool club activities involving digital technologies and software involving and supporting parents.'

- 'Outcomes and impacts for: learners with limited cognitive abilities or attributes engaged with online revision resources, online learner support, and project and after-school club activities;...for learners with challenging social attributes and abilities engaged with online learner support.'

- 'Ways parents and guardians, support workers and youth workers, counsellors and online tutors are interacting with learners across school sectors.'

While the focus of the review list was on the compulsory school sector, the evidence behind it nevertheless gathered findings from studies in other learning settings, including higher education and adult learning where applicable. The six papers presented in this special issue do provide us with a greater depth and breadth of knowledge in certain of these areas of gaps. They inform us about:
- The role of online environments in supporting group work with individuals on the autistic spectrum.

- The use of video production to support communication and engagement for those with intellectual disabilities.

- The role of mobile devices in supporting those with disabilities.

For this special issue, some key questions were listed that prospective authors might wish to address. The authors of this special issue have addressed these questions, in the following ways:

- How can digital technologies support inclusive approaches to learning? Authors have provided evidence of how this has been achieved in specific cases in university and adult learning settings.

- What is the current state of play with regard to research in this field? Authors have provided evidence from reviews of practice and research, in terms of university online learning provision, and ethical consent for learners in compulsory education settings.

- How is research looking at this issue, not just from a research perspective, but also from a practice and policy perspective? Authors have provided evidence that researchers in this field are actively involved in drawing data from learners and teachers, and focusing this in ways that can inform policy at a range of levels.

- What has been done to date, and what needs to be done next? Authors have provided evidence of progress in this field, and while their important contributions are acknowledged, it is clear that more remains to be done, if we are to support the wide range of individuals whose voices need to be brought out and heard, so that we can consider better how to be involved with and enhance their learning, assuring their social engagement.

I record my thanks and sincere appreciation to the authors of the papers contained in this special issue, as well as to the reviewers of those papers. Without these contributions, we would be all the less aware and less prepared for our future.

\section{Conflict of Interests}

The author declares no conflict of interests.

\section{References}

Bijker, W. E., Hughes, T. P., Pinch, T., \& Douglas, D. G. (2012). The social construction of technological systems: New directions in the sociology and history of 
technology. Cambridge, MA: MIT Press.

Burgstahler, S. (2015). Opening doors or slamming them shut? Online learning practices and students with disabilities. Social Inclusion, 3(6), 69-79.

Campigotto, R., McEwen, R., \& Epp, C. D. (2013). Especially social: Exploring the use of an iOS application in special needs classrooms. Computers \& Education, 60, 74-86.

Coomey, M., \& Stephenson, J. (2001). Online learning: It is all about dialogue, involvement, support and control-According to the research. In J. Stephenson (Ed.), Teaching and learning online: Pedagogies for new technologies. London: Kogan Page.

Davidson, A.-L. (2015). A collaborative action research about making self-advocacy videos with people with intellectual disabilities. Social Inclusion, 3(6), 16-28.

Doyle, D. (2010). Immersed in learning: Supporting creative practice in virtual worlds. Learning, Media and Technology, 35(2), 99-110.

Dutta, S., Geiger, T., \& Lanvin, B. (2015). The global information technology report 2015. ICTs for inclusive growth. Geneva: World Economic Forum. Retrieved from http://www3.weforum.org/docs/WEF_Global_ IT_Report_2015.pdf

Hardman, E. (2015). How pedagogy 2.0 can foster teacher preparation and community building in special education. Social Inclusion, 3(6), 42-55.

Hayhoe, S., Roger, K., Eldritch-Böersen, S., \& Kelland, L. (2015). Developing Inclusive Technical Capital beyond the Disabled Students' Allowance in England. Social Inclusion, 3(6), 29-41.

International Telecommunication Union (ITU). (2015). ICT facts and figures. Retrieved from http://www. itu.int/en/ITU-D/Statistics/Documents/facts/ICTFacts Figures2015.pdf

Kim, P., Hagashi, T., Carillo, L., Gonzales, I., Makany, T.,
Lee, B., \& Gàrate, A. (2011). Socioeconomic strata, mobile technology, and education: A comparative analysis. Educational Technology Research and Development, 59(4), 465-486.

McDowell, J. (2015). A black swan in a sea of white noise: Using technology-enhanced learning to afford educational inclusivity for learners with Asperger's Syndrome. Social Inclusion, 3(6), 7-15.

Palaigeorgiou, G., Triantafyllakos, G., \& Tsinakos, A. (2011). What if undergraduate students designed their own web learning environment? Exploring students' web 2.0 mentality through participatory design. Journal of Computer Assisted Learning, 27(2), 146-159.

Parsons, S. (2015). The potential of digital technologies for transforming informed consent practices with children and young people in social research. Social Inclusion, 3(6), 56-68.

Passey, D. (2013). Inclusive technology enhanced learning: Overcoming cognitive, physical, emotional and geographic challenges. New York, NY: Routledge.

Resta, P., \& Laferrière, T. (2008). Issues and challenges related to digital equity. In J. Voogt \& G. Knezek (Eds.), International handbook of information technology in primary and secondary education (pp. 765778). New York, NY: Springer.

Richardson, J. T. E. (2012). Face-to-face versus online tuition: Preference, performance and pass rates in white and ethnic minority students. British Journal of Educational Technology, 43(1), 17-27.

The Metiri Group. (2006). Technology in schools: What the research says. San José, CA: Cisco Systems.

Vaughn, M. G., Wexler, J., Beaver, K. M., Perron, B. E., Roberts, G., \& Fu, Q. (2011). Psychiatric Correlates of behavioral indicators of school disengagement in the United States. Psychiatric Quarterly, 82, 191-206.

\section{About the Author}

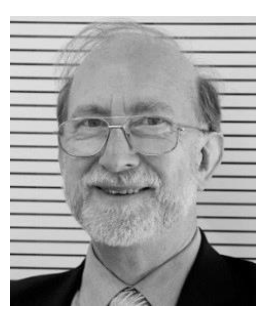

\section{Dr. Don Passey}

Don Passey is Professor and Director of the Centre for Technology Enhanced Learning (researching 'developing inclusive uses of technologies for teaching and learning'), and Director of Studies for the Doctoral Programme in e-Research and Technology Enhanced Learning (with some 100 doctoral students studying worldwide). A long-standing member of the international federation for information processing (IFIP), he is vice-chair of the Technical Committee on education, and of a Working Group exploring information technology in education management. 